\title{
PEMBELAJARAN REGULASI KENDIRI PELAJAR DALAM BAHASA ARAB: SEJAUH MANA PENGAJARAN GURU MEMAINKAN PERANAN?
}

\section{SELF-REGULATED LEARNING IN ARABIC LANGUAGE: HOW TEACHERS PLAY THEIR ROLES?}

\author{
Mohammad Haafiz bin Ahmid ${ }^{1}$ \\ Fakulti Psikologi dan Pendidikan, Universiti Malaysia Sabah (UMS) Malaysia. \\ (Email: isoginawo@gmail.com) \\ Mohd Khairuddin@Jerry bin Abdullah² \\ Fakulti Psikologi dan Pendidikan, Universiti Malaysia Sabah (UMS) Malaysia. \\ (Email: khair@ums.edu.my)
}

Received date: 08-07-2019

Revised date: 15-07-2019

Accepted date: 16-07-2019

Published date: 12-09-2019

To cite this document: Ahmid, M. H., \& Abdullah, M. K. J. (2019). Pembelajaran Regulasi Kendiri dalam Bahasa Arab: Sejauh Mana Pengajaran Guru Memainkan Peranan?. International Journal of Education, Psychology and Counseling, 4 (32), 108-118.

DOI: $10.35631 /$ IJEPC.4320011

\begin{abstract}
Abstrak: Pembelajaran regulasi kendiri membolehkan pelajar menjadi aktif dan autonomi dalam pembelajaran mereka yang merangkumi aspek metakognitif, motivasi dan tingkah laku untuk mencapai objektif pembelajaran mereka sendiri. Dalam pembelajaran bahasa Arab di sekolah menengah, beberapa kajian lepas mendapati kebergantungan pelajar tehadap guru sepenuhnya untuk mendapatkan pengetahuan. Pelajar kurang didedahkan dengan pembelajaran regulasi kendiri yang bepotensi meningkatkan kemampuan belajar secara aktif. Guru kurang mempromosikan pembelajaran regulasi kendiri kerana mereka sendiri mungkin tidak menguasai cara tersebut. Hal ini boleh menyebabkan pelajar menjadi pasif di tambah lagi Bahasa Arab merupakan mata pelajaran yang mencabar bagi yang bukan penutur jati. Oleh yang demikian, kajian ini telah menjelaskan keberkesanan pengajaran guru dalam menggalakkan pembelajaran regulasi kendiri dalam kalangan pelajar bahasa Arab. Pendekatan kuantitatif digunakan dalam kajian ini serta Student Evaluation of Teaching Effectiveness Rating Scales (SETERS) dan Motivated Strategies for Learning Questionnaire (MSLQ) sebagai instrumen kajian. Data dikumpul dari 542 pelajar Bahasa Arab dan diproses dengan analisis Korelasi Pearson. Secara keseluruhan, kajian ini mendapati hubungan signifikan antara guru yang mengajar dan pembelajaran kendiri di kalangan pelajar. Oleh itu, guru perlu memastikan pengajaran mereka dapat merangsang dan menggalakkan pembelajaran regulasi kendiri dalam kalangan pelajar untuk meningkatkan prestasi bahasa Arab di sekolah.
\end{abstract}

Kata Kunci: Pembelajaran Regulasi Kendiri, Pengajaran Guru, Pelajar Bahasa Arab 


\begin{abstract}
Self-regulated learning enables students to be active and autonomous in their way of learning that includes metacognitive, motivation and behavior aspects to achieve their own learning objectives. In Arabic learning for secondary schools, a recent studies have found that students are fully hoping for teachers-centered to gain knowledge. However, lack of promotion for self-regulated learning can cause students to be passive in determining how to choose proper way of learning, in addition Arabic language is one of the most challenging subjects. This study attempts to explain the role of teachers in their teaching with students' self-regulated learning in Arabic language. The quantitative approach was used in this study as well as the Students' Evaluation of Teaching Effectiveness Rating Scale (SETERS) and Motivated Strategies for Learning Questionnaire (MSLQ) as the instrument of study. Data were collected from 542 form 4 religious-oriented students and processed with Pearson Correlation analysis. Overall, the study found a moderate and positive significant relationship between teachers teaching and self-regulated learning among students. Therefore, teachers need to monitor their teaching approach that can stimulate and enhance self-regulated learning among students to improve Arabic language performance in schools.
\end{abstract}

Keywords: Self-regulated Learning, Teachers Teaching, Arabic Language Students

\title{
Pengenalan
}

Pembelajaran regulasi kendiri disebutkan oleh Zimmerman dan Martinez Pons (1986) dan Pintrich (2000) sebagai proses pembelajaran yang aktif yang melibatkan aspek metakognitif, motivasi dan tingkah laku untuk mencapai objektif pembelajaran yang ditetapkan oleh pelajar sendiri. Melalui pembelajaran regulasi kendiri, pelajar sendiri akan menetapkan sasaran kemudian merancang cara belajar untuk mencapai sasaran tersebut. Seterusnya melaksanakan cara belajar tersebut sambil menyelia dan mengawal persekitran dan personalnya agar pembelajaran tersebut tetap berada pada landasannya. Akhir sekali pelajar akan menilai semula pembelajarannya bagi tujuan penambah baikan berdasarkan sasaran yang dicapai.

Pelajar yang mengamalkan pembelajaran regulasi kendiri dapat meningkatkan prestasi akademik mereka (Melissa, 2010; Panadero \& Alonso-Tapia, 2014; Pintrich, 2000; Zimmerman, 1990). Dalam pembelajaran Bahasa Arab di sekolah menengah, pembelajaran regulasi kendiri adalah antara jalan penyelesaian yang boleh dianggap sesuai dengan pelajar. Hal ini kerana berdasarkan beberapa laporan kajian lepas menyebutkan bahawa pelajar kini masih lagi mengamalkan pembelajaran berpusatkan guru dan mengharap segala pengetahuan hanya diperoleh daripada guru semata-mata (Muhamad Suhaimi \& Mohd Yusof, 2014). Manakala dalam pembelajaran Bahasa Arab, pengajaran berasaskan terjemahan di tambah kefahaman yang kurang di kalangan pelajar bukan penutur jati telah menjadikan pelajar bersikap pasif dalam pembelajaran mereka (Rosni, 2009, 2012, 2015).

Guru seharusnya memainkan peranan penting dalam menggalakkan pelajar dengan pembelajaran regulasi kendiri sebagai amalan dalam tingkah laku belajar di kalangan pelajar. Tambahan pula, Bahasa Arab adalah subjek yang wajib dipelajari oleh pelajar yang Bahasa Arab dan mendudukinya dalam peperiksaan awam (PT3, SPM). Maka usaha belajar yang teratur amat diperlukan bagi memastikan pembelajaran Bahasa Arab lebih berkesan. Melissa (2010) dan Costa-Ferreira dan Veiga-Simão (2012) merekodkan betapa peluang untuk pembelajaran regulasi kendiri di kalangan pelajar perlu dibuka seluas-luasnya kepada pelajar dengan mengambil pendekatan pengajaran yang bersesuaian dengan keupayaan pelajar terutama dalam pembelajaran bahasa asing. Keupayaan pelajar merancang, melaksana dan 
menilai pembelajarannya menjadikan mereka pelajar yang aktif dan sentiasa berusaha untuk mendapatkan pengetahuan dengan apa cara sekali pun agar dapat menepati sasaran yang ditetapkan. Justeru, pengajaran guru perlu menjurus dan menggalakkan pengamalan pembelajaran regulasi kendiri sebagai salah satu cara untuk meningkatkan prestasi Bahasa Arab di sekolah menengah.

\section{Penyataan Masalah}

Pembelajaran Bahasa Arab memerlukan usaha gigih dan berterusan daripada pelajar untuk mempelajarinya. Persekitaran pelajar seperti rakan sebaya dan guru berpotensi mempengaruhi pembelajaran pelajar (Ghazali, Nik Mohd Rahimi, Parilah, \& Wan Haslina, 2011). Tambahan pula dalam konteks negara yang bukan penutur jati bahasa ini maka pelajar bukan sahaja perlu berkeyakinan untuk belajar bahkan perlukan cara belajar yang lebih berkesan. Secara umum, perkembangan dan pencapaian pelajar dalam Bahasa Arab di Malaysia masih di tahap yang rendah dan kurang memuaskan serta belum mencapai objektif pelaksanaannya (Abdul Hakim, Ab. Aziz, Wan Ismail \& Hafisah, 2014; Zamri, Ezad Azraai, Khaulah, Muhamad Ridzuan \& Zulazhan, 2014). Faktor kelemahan perancangan dan pelaksanaan cara belajar yang berkesan dan terkawal antara penyebab situasi penncapaian akademik pelajar merundum dan tidak menepati sasaran (Cetin, 2015; Dent \& Koenka, 2015).

Di samping itu, budaya pengajaran berpusatkan guru yang masih menjadi kelaziman dalam sistem pendidikan kini sehingga akhirnya melahirkan pelajar yang hanya mencapai gred peperiksaan yang baik namun penguasaan ilmu yang kurang (Manukaram, Melissa, \& Shahizan, 2014; Muhamad Suhaimi \& Mohd Yusof, 2014; Rosni, 2012). Pergantungan guru dan pelajar semata-mata terhadap peperiksaan awam sebagai penanda aras iaitu ujian bertulis untuk menilai suatu penguasaan bahasa menyebabkan pelajar tiada kemampuan menyelenggara pembelajarannya secara optimum dan holistik. Dapatan ini bersesuaian dengan beberapa kajian yang menyebutkan pembelajaran Bahasa Arab antara subjek yang masih mengharapkan guru semata-mata sebagai sumber utama bagi pelajar bagi mendapatkan pengetahuan dan kemahiran Bahasa Arab (Rosni, 2009).

Pelajar Bahasa Arab di sekolah menengah juga mungkin kurang diberikan pendedahan tentang kemahiran untuk melaksanakan pembelajaran regulasi kendiri secara lebih berkesan. Hal ini pernah diutarakan oleh Melissa (2010) dan Peeters et al. (2016) bahawa pelajar kurang kemahiran pembelajaran regulasi kendiri adalah disebabkan guru sendiri kurang mahir dalam kemahiran tersebut. Halim (2012) menyatakan bahawa penerapan strategi pembelajaran yang bersesuaian dengan karakteristik cara belajar berpotensi mempengaruhi prestasi akademik pelajar. Perihal ini mungkin berlaku kerana guru kurang memberikan maklum balas terhadap perkembangan akademik pelajar di samping kurang berdamping dengan pelajar untuk membantu mereka pada masa yang diperlukan. Rosni (2012) turut menyebutkan beberapa isu lain dalam pembelajaran bahasa Arab seperti kurang latih tubi, penggunaan alat bantu mengajar dan bahan bacaan tambahan, kurang komunikasi bahasa dan aktiviti bahasa serta sikap pasif pelajar. Bahkan, pelajar Bahasa Arab juga didapati menghadapi pemasalahan yang sama walaupun mereka telah belajar Bahasa Arab sejak dari peringgkat rendah lagi (Ali, 2012; Syed Mohd Annas, Abdul Halim, Mohd Sham, Maimun Aqsha, \& Amran, 2017).

Sehubungan itu, kajian ini akan cuba mengenal pasti perkaitan pengajaran guru yang boleh mempengaruhi pembelajaran regulasi kendiri di kalangan pelajar Bahasa Arab di sekolah menengah. Potensi untuk menjadikan pembelajaran regulasi kendiri sebagai cara mempelajari Bahasa Arab dengan lebih efisien akan lebih positif sekiranya guru berperanan sebagai 
pembimbing boleh membentuk aktiviti pembelajaran pelajar secara pembelajaran regulasi kendiri. Costa-Ferreira dan Veiga-Simão (2012) dalam kajiannya pernah mengesahkan bahawa perubahan pada pendekatan pengajaran guru boleh membantu menggalakkan pelajar dengan pembelajaran regulasi kendiri bermula dari peringkat sekolah rendah lagi agar pelajar boleh menerima tugasan akademik yang diberikan dan menyelesaikannya dengan berkesan.

\section{Sorotan Literatur}

\section{Pembelajaran Regulasi Kendiri}

Kajian Toland dan Ayala (2005) telah menemui tiga konstruk utama yang merujuk kepada pengajaran guru yang berkesan iaitu penyampaian informasi pelajaran, interaksi guru-pelajar dan pengaturan pembelajaran pelajar. Kajian tersebut kemudiannya telah membina sebuah instrumen untuk menentukan tahap pengajaran seseorang guru secara keseluruhan menurut perspekstif dan penilaian pelajar. Dalam erti kata yang lain, kajian tersebut berpendapat bahawa guru merupakan antara individu yang bertanggungjawab membentuk aktiviti pembelajaran pelajar mengikut kesesuaian pelajar.

Antara aktiviti pembelajaran yang dianggap strategik dan sistematik dalam kalangan pelajar adalah pembelajaran regulasi kendiri. Hal ini disebabkan oleh rangkuman beberapa aspek regulasi kendiri seperti perancangan, aktiviti pelaksanaan dan refleksi yang dilakukan sendiri oleh pelajar untuk mencapai objektif pembelajaran samada yang ditetapkannya sendiri atau mengikut ketetapan guru (Pintrich, 2004; Zimmerman, 2002). Walau bagaimana pun, bagi pelajar yang aktif, pembelajaran regulasi kendiri bukan satu kesukaran bagi mereka kerana yakin dengan kemahiran dan pengetahuan diri yang mampu untuk melaksanakan tugasan atau aktiviti pembelajaran secara bebas dan autonomi (Manukaram et al., 2014; Melissa, 2010). Guru tidak menghadapi masalah yang besar untuk membimbing dan mengajar pelajar aktif untuk menguasai strategi belajar yang berbeza. Walau bagaimana pun, pelaksanaan pembelajaran regulasi kendiri terhadap pelajar yang pasif memerlukan sedikit pemerhatian dan bimbingan yang berterusan bagi mengelakkan perkara yang tidak diingini berlaku. Bukan itu sahaja, dalam sesetengah situasi, pelajar aktif yang terlalu berkeyakinan diri boleh menghadapi situasi yang sama sekiranya tiada pemerhatian guru yang berterusan.

\section{Pembelajaran dan Pengajaran Bahasa Arab}

Bahasa Arab merupakan mata pelajaran yang penting di sekolah menengah yang mempunyai pelajar berorientasikan agama. Kepentingan bahasa tersebut selaras dengan saranan PPPM (2013-2025) dan Sarana Ibubapa yang menggariskan keperluan dan kemampuan pelajar menguasai bahasa selain Bahasa Malaysia. Oleh itu, Bahasa Arab telah mula dipelajari sejak dari peringkat rendah hingga ke institut pengajian tinggi. Walau bagaimana pun, prestasi dan objektif yang digariskan KPM untuk Bahasa Arab masih di tahap yang kurang memuaskan (Abdul Hakim et al., 2015). Hal ini disebabkan oleh pelajar tidak menguasai cara belajar yang betul dan berkesan seperti pembelajaran regulasi kendiri. Dalam masa yang sama, guru Bahasa Arab juga mungkin tidak mahir dengan pembelajaran tersebut. Keadaan ini menyebabkan guru lebih selesa mendominasi aktiviti pembelajaran dan kurang memberi peluang kepada pelajar untuk memberi pandangan dan idea tentang isi pelajaran yang disampaikannya (Mohammad Haafiz et al., 2018). Justeru memperkasa pembelajaran regulasi kendiri di kalangan pelajar merupakan inisiatif guru untuk meningkatkan pencapaian Bahasa Arab di sekolah.

Pengajaran tentang pembelajaran regulasi kendiri di kalangan pelajar mungkin boleh dilakukan dengan teratur dan secara semula jadi oleh guru. Schunk dan Usher (2012) dan Zimmerman 
dan Schunk (1989) menyatakan bahawa pelajar perlu diberi peluang untuk menggunakan apa sahaja kaedah belajar yang mereka rasakan sesuai dengan kemahiran dan pengetahuan mereka. Kenyataan ini bertepatan dengan saranan Rosni (2009) yang mencadangkan agar guru tidak perlu terlalu terikat dengan kaedah pengajaran yang lama iaitu baca dan terjemah dalam pembelajaran Bahasa Arab yang banyak berpusatkan guru sebagai sumber utama. Perihal ini boleh menjadikan pelajar pasif yang bertentangan dengan syarat pembelajaran regulasi kendiri iaitu pelajar yang aktif. Sebagai contoh dalam kemahiran membaca (qiro'ah), pelajar diberikan buku kanak-kanak berbahasa Arab sebagai bahan bacaan tambahan samada di bilik darjah, di asrama atau di rumah. Bukan itu sahaja, buku berbentuk komik atau apa sahaja bahan bacaan Bahasa Arab yang boleh didapati pelajar adalah digalakkan kerana ia membantu pemahaman pelajar terhadap teks yang dibaca sehingga nanti mereka akan lebih mahir dalam pengucapan teks dan ungkapan-ungkapan yang diberikan secara tepat dan jelas.

Walau bagaimana pun, Winne (2010) pernah menyatakan bahawa guru tidak dibekalkan dengan pengetahuan tentang kemahiran belajar yang boleh mereka sampaikan kepada pelajar, namun perihal pemasalah ini tidak boleh ditujukan kepada guru semata-mata kerana reka bentuk kurikulum pendidikan guru telah dibentuk oleh pihak yang lebih profesional dalam bidang pendidikan. Keadaan ini boleh menjadikan pelajar pasif dan guru pula kekurangan idea untuk membantu pelajar tentang kemahiran belajar yang sesuai dengan tahap kognitif mereka. Pembelajaran Bahasa Arab di Malaysia menurut Rosni $(2009,2012)$ banyak berharap kepada guru dan pelajar kurang berusaha di luar pengajaran bilik darjah. Hal ini bukan sahaja menyebabkan kemerosotan prestasi Bahasa Arab pelajar, bahkan berpotensi menyebabkan pembelajaran berpusatkan guru yang berterusan.

\section{Objektif Kajian}

Kajian ini bertujuan untuk menentukan hubungan antara pengajaran guru dengan pembelajaran regulasi kendiri di kalangan pelajar Bahasa Aran di sekolah menengah. Fokus mata pelajaran adalah Bahasa Arab yang wajib dipelajari oleh pelajar dan mendudukinya dalam peperiksaan awam seperti PT3, SPM dan STPM.

\section{Metodologi Kajian}

\section{Reka Bentuk dan Sampel Kajian}

Dalam kajian ini, reka bentuk kuantitatif digunakan bagi menganalisis dapatan yang menjadikan angka sebagai dapatan kajian. Kaedah tinjauan bukan eksperimen dijalankan untuk proses pengumpulan data kajian kerana menurut Lay dan Khoo (2015), kajian tinjauan merupakan kajian yang sesuai untuk mengetahui pemikiran, perasaan dan tingkah laku tertentu dalam populasi yang besar. Teknik pensampelan rawak berstrata dijalankan bagi mendapatkan responden daripada beberapa sekolah menengah yang mempunyai pelajar yang mengambil bahasa Arab secara wajib iaitu sekolah menengah kebangsaan (SMK), sekolah menengah kebangsaan agama (SMKA) dan sekolah menengah agama negeri (SMAN). Seramai 542 sampel pelajar tingkatan 4 daripada SMK, SMKA dan SMAN yang telah memberi respon terhadap soal selidik boleh dianalisis. Pemilihan pelajar tingkatan 4 berpadanan dengan pandangan Kamarul Shukri, Mohamed Amin, Nik Mohd Rahimi dan Zamri (2009) yang menyatakan bahawa tempoh empat tahun (tingkatan 1 hingga 4) memadai untuk pelajar membina dan menentukan tingkah laku belajar yang sesuai dalam pembelajaran bahasa 


\section{Instrumen Kajian}

Instrumen yang digunakan dalam kajian ini adalah Students' Evaluation of Teaching Effectiveness Rating Scale (SETERS) yang dibina Toland dan Ayala (2005) yang direspon oleh pelajar bagi menilai pengajaran guru Bahasa Arab di sekolah masing-masing. Manakala pembelajaran regulasi kendiri pelajar pula dikutip menggunakan instrumen yang dibina oleh Pintrich dan De Groot (1990) iaitu Motivated Strategies for Learning Questionnaire (MSLQ) melalui Self-Regulated Learning Strategies Scale. Data yang diperolehi telah dianalisis dalam perisian SPSS versi 17.0 menggunakan analisis korelasi pearson bagi menentukan hubungan antara pengajaran guru dan pembelajaran regulasi kendiri pelajar. Selanjutnya, analisis korelasi juga dijalankan antara konstruk-konstuk pengajaran guru dengan pembelajaran regulasi kendiri.

\section{Dapatan Kajian}

Hasil analisis mendapati andaian hubungan antara pengajaran guru dan pembelajaran regulasi kendiri beserta konstruk-konstruknya dibuktikan secara statistik. Jadual 1 menunjukkan hasil analisis korelasi pendekatan pengajaran guru didapati mempunyai hubungan yang signifikan dengan pembelajaran regulasi kendiri $(r=.308, p<.01)$ secara sederhana namun positif. Selanjutnya adalah perincian tentang konstruk pendekatan pengajaran guru dengan pembelajaran regulasi kendiri seperti yang dilaporkan dalam jadual 2. Dapatan korelasi menunjukkan hubungan yang positif dan sederhana rendah namun signifikan antara pembelajaran regulasi kendiri dengan ketiga-tiga konstruk pendekatan pengajaran guru iaitu konstruk penyampaian informasi pelajaran $(r=.287, p<.01)$, konstruk interaksi guru-pelajar $(r=.246, p<.01)$ dan konstruk pengaturan pembelajaran pelajar $(r=.284, p<.01)$.

\section{Jadual 1 Analisis Korelasi Pengajaran Guru dan Pembelajaran Regulasi Kendiri}

Pembelajaran regulasi kendiri

\begin{tabular}{|c|c|}
\hline Pengajaran Guru & $.308 * *$ \\
\hline
\end{tabular}

\section{Jadual 2 Analisis Korelasi konstruk pengajaran guru dan pembelajaran regulasi kendiri}

Pembelajaran regulasi kendiri

\begin{tabular}{lc}
\hline Penyampaian informasi pelajaran & $.287^{* *}$ \\
Interaksi guru-pelajar & $.246^{* *}$ \\
Pengaturan pembelajaran pelajar & $.284^{* *}$ \\
\hline Correlation is significant at the 0.01 level (2-tailed) &
\end{tabular}

Secara keseluruhan, hasil analisis merekodkan hubungan yang sederhana rendah pada nilai korelasi .2 ke nilai .3 dan berada pada aras signifikan $p<.01$. Oleh yang demikian, dapatan korelasi ini telah menepati objektif yang ingin dicapai iaitu menentukan hubungan signifikan antara pengajaran guru dan pembelajaran regulasi kendiri di kalangan pelajar Bahasa Arab. Dapatan ini juga menjelaskan bahawa peningkatan pada pengajaran guru akan meningkatkan pembelajaran regulasi kendiri di kalangan pelajar, dan semakin menurun tahap pengajaran guru maka tahap pembelajaran regulasi kendiri di kalangan pelajar juga akan turut menurun. 


\section{Perbincangan}

Seterusnya dibincangkan hasil analisis korelasi antara pendekatan pengajaran guru dan pembelajaran regulasi kendiri yang didapati berhubung secara signifikan pada aras yang sederhana. Analisis ini menunjukkan bahawa semakin meningkat pendekatan pengajaran guru maka pembelajaran regulasi kendiri di kalangan pelajar akan turut meningkat dan begitu juga sebaliknya apabila pendekatan pengajaran guru menurun maka pembelajaran regulasi kendiri juga menurun.

Pembelajaran Bahasa Arab memerlukan pengupayaan guru untuk membantu pelajar agar dapat belajar dengan lebih berkesan tanpa terlalu bergantung pada mereka. Hubungan yang positif tapi sederhana menggambarkan guru Bahasa Arab masih mengamalkan budaya berpusatkan guru sehingga menyebabkan pelajar menjadi pasif (Rosni, 2009). Pelajar lebih mengharapkan guru untuk memberikan informasi tentang isi pelajaran dan kurang berusaha sama ada secara individu atau berkumpulan untuk mendapatkan maklumat pelajar yang lebih terperinci secara teratur. Fenomena ini mungkin disebabkan guru juga kurang menunjukkan pelajar jalan atau cara belajar yang sesuai dengan topik-topik yang diajar. Oleh itu, tahap pembelajaran regulasi kendiri pelajar berada pada aras yang kurang memberangsangkan. Tambahan pula, guru juga mungkin bertindak dengan cara menentukan apa yang perlu dan tidak perlu dipelajari hanya untuk memenuhi keperluan ujian atau peperiksaan semata-mata sahaja.

Selain itu, konstruk-konstruk pendekatan pengajaran guru juga didapati berhubung secara signifikan dengan pembelajaran regulasi kendiri namun pada aras yang sederhana dan lemah. Perihal ini menunjukkan bahawa guru Bahasa Arab berkemungkinan kurang memberi pendedahan tentang cara-cara untuk lebih berdikari dalam pembelajaran tanpa terlalu terikat dengan aktiviti yang dirancang dan dilaksana oleh guru di sekolah. Sekiranya guru melaksanakan pendekatan pengajaran yang boleh mencetuskan tingkah laku belajar yang lebih kreatif dan bebas di kalangan pelajar, kemungkinan untuk peningkatan prestasi Bahasa Arab akan lebih positif. Hanif dan Kaseh (2016) menyatakan interaksi positif antara guru dan pelajar dalam proses pengajaran dan pembelajaran boleh menggalakkan penglibatan pelajar dalam proses pembelajaran yang meningkatkan penguasaan bahasa mereka. Kenyataan ini menyokong dapatan kajian ini apabila tahap interaksi guru-pelajar yang sederhana menyebabkan aspek perbincangan tentang strategi pembelajaran sesuai menjadi rendah. Pembelajaran Bahasa Arab memerlukan kerjasama erat antara guru dan pelajar terutama sekali apabila menekankan soal tatabahasa (nahu saraf) yang perlukan latihan berterusan dengan bimbingan guru. Di samping itu, aktiviti pembacaan dan pemahaman teks Arab tidak perlu diterjemahkan sepenuhnya oleh guru bahkan menunjukkan kaedah untuk menterjemah kepada pelajar agar mereka lebih berdikari dan mahir menggunakan bahan bantu seperti kamus atau perisian elektronik tertentu.

Justeru, bimbingan guru tentang aktiviti pembelajaran sistematik seperti pembelajaran regulasi kendiri secara eksplisit dan terperinci dijangkakan boleh membina tingkah laku pembelajaran yang aktif dan berdikari dalam kalangan pelajar. Guru boleh memperkenalkan kemahiran dan strategi kepada pelajar yang membawa ke arah pembelajaran regulasi kendiri semasa mengajar subjek atau topik tertentu agar berlaku kelangsungan dalam aktiviti pembelajaran pelajar dalam dan luar darjah. Zimmerman (2002) dan Boekaerts dan Corno (2005) menyebutkan bahawa pengajaran langsung seperti penyenaraian tentang perancangan, pelaksanaan dan refleksi serta mengajar pelajar tentang strategi dan kemahiran yang perlu dalam strategi tersebut boleh membantu pelajar mendalami dan melaksana pembelajaran regulasi kendiri dalam menjalankan tugasan yang diberikan kepada mereka. 
Sebagai contoh dalam membina karangan Bahasa Arab (Insya'), guru menerangkan isi penting yang diperlukan untuk membina karangan dengan tajuk tertentu. Apabila pelajar mula membuat karangan, guru bertindak menunjukkan cara untuk membina karangan yang baik seperti menggunakan kamus, majalah berbahasa Arab dan perbincangan rakan sebaya. Guru juga boleh menyediakan beberapa kalimah atau perkataan Arab yang berlainan namun mempunyai maksud yang sama untuk dipilih oleh pelajar. Dalam hal ini, guru perlu memberikan masa yang lebih panjang untuk memberi peluang kepada pelajar berfikir dan mencari maklumat atas faktor kekurangan dan kelemahan pelajar bukan penutur jati mencipta karangan Bahasa Arab seperti yang pernah dijelaskan oleh Muhd Zahri dan Muhd Haron (2016). Kemudian, aktiviti tersebut perlu diulang semula sekiranya berjaya membentuk kemahiran dalam kalangan pelajar. Namun jika sebaliknya, guru perlu memikirkan aktiviti lain yang boleh membantu pelajar bergerak lebih aktif.

Dapat dirumuskan bahawa, analisis korelasi telah menunjukkan hubungan signifikan yang sederhana dan positif antara pendekatan pengajaran guru dan pembelajaran regulasi kendiri. Perihal ini mencerminkan kurangnya pendedahan guru tentang cara belajar yang autonomi serta kurang memberi kebebasan kepada pelajar untuk belajar dengan cara mereka sendiri. Beberapa kajian lepas berpendapat keadaan ini berlaku kerana guru terlalu mengamalkan aktiviti belajar yang berpusatkan guru (Rosni, 2009; Manukaram et al., 2014; Muhammad Suhaimi, 2011; Zakaria, Mahalle dan Nawi, 2015) terutama dalam mata pelajaran Bahasa Arab yang dianggap mata pelajaran yang agak susah dan guru beranggapan pelajar perlu mengikut ajaran guru tanpa perlu banyak soal. Ini ditegaskan lagi daripada analisis deskriptif pendekatan pengajaran guru yang menunjukkan aras min rendah pada item yang merujuk kepada peluang yang diberikan oleh guru kepada pelajar untuk bertanya atau menyuarakan pendapat tentang apa yang dipelajari.

\section{Kesimpulan}

Zimmerman (2002) mendefinisikan pembelajaran regulasi kendiri sebagai aktiviti belajar yang merangkumi unsur metakognitif, perubahan tingkah laku dan bermotivasi untuk menentukan cara belajar yang sesuai dengan kemahiran dan pengetahuan yang sedia ada untuk mencapai sasaran yang mereka tetapkan sendiri. Dalam hal ini, keupayaan pelajar untuk menyusun, menyelia, mengawal, melaksana dan menilai sendiri pembelajarannya adalah prioriti utama pelaksanaan pembelajaran regulasi kendiri. Faktor persekitaran pelajar seperti pengajaran guru berpotensi membentuk pembelajaran regulasi kendiri di kalangan pelajar. Penjelasan dan penerangan secara eksplisit seperti membantu pelajar menetapkan matlamat di samping memberi garis panduan tentang cara pencarian maklumat pelajaran serta mudah berinteraksi apabila diperlukan.

Oleh yang demikian, kajian korelasi ini telah menunjukkan bahawa dalam pembelajaran Bahasa Arab, pengajaran guru didapati mempunyai hubung kait yang signifikan dengan pembelajaran regulasi kendiri di kalangan pelajar Bahasa Arab. Justeru, dapatan kajian ini penting bagi mengenal pasti isu yang berlaku kerana pelajar yang kurang mengamalkan pembelajaran regulasi kendiri cenderung untuk mendapat prestasi akademik yang kurang memberangsangkan (Manukaram et al., 2014; Mega, Ronconi, \& De Beni, 2014; Zimmerman \& Schunk, 1989). Oleh yang demikian, perhatian perlu diberikan oleh para guru khasnya guru Bahasa Arab dengam mengambil pendekatan pengajaran yang lebih berkesan dan tidak hanya berpusatkan guru semata-mata. Kajian akan datang seharusnya mengenal pasti gaya belajar di kalangan pelajar Bahasa Arab di samping meluaskan sampel kepada pelajar yang turut memilih Bahasa 
Arab sebagai mata pelajaran elektif. Harapan agar kajian ini dapat memberi gambaran jelas tentang perkembangan Bahasa Arab di sekolah menengah dan dapat membuka mata pihakpihak yang menggubal dasar dalam pendidikan agar dapat menepati hasrat Falsafah Pendidikan Kebangsaan.

\section{Rujukan}

Abdul Hakim, A., Ab. Aziz, S., Wan Ismail, W. A., \& Hafisah, Z. (2014). Faktor-Faktor Yang Mempengaruhi Motivasi Terhadap Pembelajaran Bahasa Arab Dalam Kalangan Pelajar Peringkat Menengah Rendah Di Sekolah Menengah Kebangsaan Agama (SMKA) Naim Lilbanat Kota Bharu Kelantan. Prosiding Seminar Pengajaran Dan Pembelajaran Bahasa Arab 2014, 1-10.

Ali, M. (2012). Pengajaran Dan Pembelajaran Bahasa Arab Tinggi Dari Perspektif Guru Sekolah Agama Bantuan Kerajaan (SABK). In Persidangan Kebangsaan Pengajaran Dan Pembelajaran Bahasa Arab 2012 (PKEBAR'12) (pp. 34-47). Retrieved from http://medcontent.metapress.com/index/A65RM03P4874243N.pdf

Boekaerts, M., \& Corno, L. (2005). Self-regulation in the classroom: A perspective on assessment and intervention. Applied Psychology: An International Review, 54(2), 199231.

Cetin, B. (2015). Academic Motivation And Self-Regulated Learning In Predicting Academic Achievement In College. Journal of International Education Research, 11(2), 95-106.

Costa-Ferreira, P., \& Veiga-Simão, A. M. (2012). Teaching Practices that Foster Self-regulated Learning: a case study. Educational Research EJournal, 1(1), 1-16. https://doi.org/10.5838/erej.2012.11.01

Dent, A. L., \& Koenka, A. C. (2015). The Relation Between Self-Regulated Learning and Academic Achievement Across Childhood and Adolescence: A Meta-Analysis. Educational Psychology Review. https://doi.org/10.1007/s10648-015-9320-8

Gamal Abdul Nasir, Z., Salwa, M., \& Aliff, N. (2015). Kajian Amalan Pengajaran Guru Bahasa Arab Sekolah Menengah di Negara Brunei Darussalam. The Online Journal of Islamic Education, 3(1), 32-40.

Ghazali, Y., Nik Mohd Rahimi, N. M. Y., Parilah, M. S., \& Wan Haslina, W. (2011). Cognitive and metacognitive learning strategies among Arabic language students. Interactive Learning Environments, 21(3), 1-11. https://doi.org/10.1080/10494820.2011.555840

Halim, A. (2012). Pengaruh Strategi Pembelajaran Dan Gaya Belajar Terhadap Hasil Belajar Fisika Siswa SMPN 2 Secanggang Kabupaten Langkat. Jurnal Tabularasa PPS UNIMED, 9(2), 1-18.

Hanif, I. H., \& Kaseh, A. B. (2016). Analisis Interaksi Guru-Pelajar dalam Kelas Pembelajaran Bahasa Arab dan Penggunaannya di Universiti Sains Islam Malaysia (USIM). International Journal of West Asian Studies, 8(1), 83-195. https://doi.org/10.22583/ijwas.2016.08.01

Kamarul Shukri, M. T., Mohamed Amin, E., Nik Mohd Rahimi, N. Y., \& Zamri, M. (2009). Language Learning Strategies and Motivation among Religious Secondary School Students. The International Journal of Language, Society and Culture, (29), 71-79. Retrieved from www.educ.utas.edu.au/users/tle/JOURNAL/

Lay, Y. F., \& Khoo, C. H. (2015). Pengenalan kepada Pendekatan Kuantitatif dalam Penyelidikan Pendidikan (4th ed.). Kota Kinabalu: Penerbit Universiti Malaysia Sabah.

Manukaram, K., Melissa, A. N. L. ., \& Shahizah, H. (2014). Pengaruh Psikologi terhadap Pembelajaran Regulasi Kendiri Murid Sekolah Rendah. Asia Pasific Journal of Educators and Education, 29, 39-54. 
Mega, C., Ronconi, L., \& De Beni, R. (2014). What makes a good student? How emotions, selfregulated learning, and motivation contribute to academic achievement. Journal of Educational Psychology, 106(1), 121-131. https://doi.org/10.1037/a0033546

Melissa, N. L. Y. A. (2010). Self-Regulated Learning: Theory and Application. Pulau Pinang: Penerbit Universiti Sains Malaysia.

Mohammad Haafiz, A., Mohd Khairuddin, A., \& Khalid, J. (2018). Pengajaran Guru dan Kepercayaan Motivasi Pelajar dalam Pembelajaran Bahasa Arab di Sekolah Menengah. Malaysian Journal of Social Sciences and Humanities, 3(3), 136-147. Retrieved from www.msocialsciences.com

Muhamad Suhaimi, T., \& Mohd Yusof, A. (2014). Impak Pengajaran dan Bimbingan Guru Pendidikan Islam Terhadap Motivasi dan Pembelajaran Terarah Kendiri Pelajar. Jurnal Pemikir Pendidikan, 5, 1-17.

Muhammad Suhaimi, T. (2011). Gaya Pertautan dan Motivasi Pelajar serta Pengajaran dan Bimbingan Guru Pendidikan Islam Terhadap Pembelajaran Terarah Kendiri (PTK) Pelajar. Universiti Malaysia Sabah.

Muhammad Zahri, A. K., \& Muhammad Haron, H. (2016). Tahap Penguasaan Penulisan Karangan Bahasa Arab Dalam Kalangan Pelajar Sekolah Agama Menengah. E-Jurnal Penyelidikan Dan Inovasi, 3(1), 123-138. https://doi.org/10.1111/j.14756765.2011.02014.x

Panadero, E., \& Alonso-Tapia, J. (2014). How do students self-regulate? Review of Zimmerman "s cyclical model of self-regulated learning. Anales De Psicología, 30, 450 462. https://doi.org/10.6018/analesps.30.2.167221

Peeters, J., De Backer, F., Kindekens, A., Triquet, K., \& Lombaerts, K. (2016). Teacher differences in promoting students' self-regulated learning: Exploring the role of student characteristics. Learning and Individual Differences, 52, 88-96. https://doi.org/10.1016/j.lindif.2016.10.014

Pintrich, P.R. (2004). A Conceptual Framework for Assessing Motivation and Self-Regulated Learning in College Students. Educational Psychology Review, 16(4), 385-407. https://doi.org/10.1007/s10648-004-0006-X

Pintrich, Paul R. (2000). Multiple goals, multiple pathways: The role of goal orientation in learning and achievement. Journal of Educational Psychology, 92(3), 544-555. https://doi.org/10.1037/0022-0663.92.3.544

Pintrich, Paul R., \& de Groot, E. V. (1990). Motivational and self-regulated learning components of classroom academic performance. Journal of Educational Psychology, 82, 33-40. https://doi.org/10.1037/0022-0663.82.1.33

Rosni, S. (2009). Isu Pembelajaran Bahasa Arab di Malaysia. Negeri Sembilan: Penerbit USIM.

Rosni, S. (2012). Isu pembelajaran bahasa Arab. In Persidangan Kebangsaan Pengajaran Dan Pembelajaran Bahasa Arab 2012 (PKEBAR’12) (Vol. 2012, pp. 286-300).

Rosni, S. (2015). Pendekatan Pengajaran Kosa Kata Bahasa Arab Di Peringkat Menengah Rendah : Kajian Kepada Guru Bahasa Arab Di Sekolah Menengah Kebangsaan Agama Kuala Lumpur (Smkakl). D, 1, 1-15. https://doi.org/10.1017/CBO9781107415324.004

Schunk, D. H., \& Usher, E. L. (2012). Social Cognitive Theory and Motivation. In The Oxford Handbook of Human https://doi.org/10.1093/oxfordhb/9780195399820.013.0002

Syed Mohd Annas, S. A. H., Abdul Halim, M., Mohd Sham, K., Maimun Aqsha, L., \& Amran, M. A. (2017). Kelemahan Pelajar-pelajar Sekolah Menengah Kebangsaan Agama (SMKA) dan Sekolah Agama Menengah (SAM) dalam Penguasaan Topik Terpilih 
dalam Tatabahasa Arab. ASEAN Comparative Education Research Journal on Islam and Civilization (ACER-J), 1(2), 67-78.

Toland, M. D., \& Ayala, R. J. De. (2005). A Multilevel Factor Analysis of Students' Evaluations of Teaching. Educational and Psychological Measurement, 65(2), 272296. https://doi.org/10.1177/0013164404268667

Winne, P. H. (2010). Bootstrapping learner's self-regulated learning. Psychological Test and Assessment Modeling, 52(4), 472-490.

Zamri, A., Ezad Azraai, J., Khaulah, R., Muhamad Ridzuan, A. L., \& Zulazhan, A. H. (2014). Attitudes of Distance Learning Students At Ukm ' S Faculty of Islamic Studies Towards Learning. Turkish Online Journal of Distance Education, 15(1), 174-188. Retrieved from www.eric.ed.gov

Zimmerman, B. J. (1990). Self-Regulated Learning and Academic Achievement: An Overview. Educational Psychologist. https://doi.org/10.1207/s15326985ep2501

Zimmerman, B. J. (2002). Becoming learner: Self-regulated overview. Theory into Practice, 41(2), 64-70. https://doi.org/10.1207/s15430421tip4102_2

Zimmerman, B. J., \& Martinez Pons, M. (1986). Development of a Structured Interview for Assessing Student Use of Self-Regulated Learning Strategies. American Educational Research Journal, 23(4), 614-628. https://doi.org/10.2307/1163093

Zimmerman, B. J., \& Schunk, D. H. (1989). Self-Regulated Learning and Academic Achievement: Theory, Research and Practice. New York: Springer-Verlag. 